\title{
TRABALHO FORÇADO E DEGRADANTE NO SETOR DA MARINHA MERCANTE INTERNACIONAL NO SÉCULO XXI: ATUALIZAÇÕES E COMPARAÇÕES COM OS TRABALHOS DE TERRA
}

\author{
FORCED AND DEGRADING LABOUR IN THE XXI CENTURY'S \\ INTERNATIONAL SEAFARING SECTOR: UPDATES AND \\ COMPARISONS WITH LABOUR ON LAND
}

VALTER ZANIN*

\section{RESUMO}

$\mathrm{O}$ artigo discute as formas de trabalho forçado e degradante no setor da marinha mercante internacional no século XXI, elaborando estimativas sobre o número e nacionalidade dos marinheiros sujeitos a estas formas de coerção. Os traços distintivos do trabalho maritimo são contrários daqueles característicos de grande parte do trabalho forçado em terra: de fato, o trabalho marítimo é estratégico, produtivo, altamente regulamentado pelos Estados e organizações internacionais, apresenta altissima intensidade de capital, elevados salários e uma força de trabalho qualificada e internacionalizada - tanto que a OIT nunca mencionou os marinheiros nas suas estimativas do trabalho forçado e que até hoje existe somente uma monografia, publicada em 2007 pelo autor deste artigo, discutindo sistematicamente do assunto e elaborando as relativas estimativas. No artigo, são descritas as principais formas de trabalho forçado no mar no início do século XXI, atualizando e especificando as estimativas apresentadas em 2007. Entre outras fontes, são analisados os relatórios anuais do Committee of Experts on the Application of Conventions and Recommendations (CEACR) da OIT, que monitaram a conformidade dos códigos de navegação dos Países que assinaram a Convenção OIT n. 105, de 1957 sobre o trabalho forçado. Desde que a OIT não considera nas suas estimativas do trabalho forçado nem os casos denunciados pelo mesmo CEACR, o artigo, a partir de uma possivel generalizaçao dos métodos elaborados pelo

\begin{abstract}
The article discusses the forms of forced and degrading labour in the international merchant marine in the 21st century, by estimating number and nationality of the seafarers subjected to these forms of coercion. The distinctive features of seafaring are contrary to the characteristics of the largest part of forced labour on land: in fact, the maritime labour is strategic, productive, highly regulated by States and International organizations, has very high capital intensity, high salaries and a skilled and internationalized workforce - so much so that the ILO has never mentioned the seafarers in its estimates on forced labour and until now there is only one monograph, published in 2007 by the author of this article, discussing systematically the argument and developing related estimates. This article describes the main forms of forced labour at sea in the 21st century, updating and specifying the estimates presented in 2007. Among other sources, are analyzed the annual reports of the Committee of Experts on the Application of Conventions and Recommendations (CEACR) of the $I L O$, which monitor the compliance of the navigation's codes of the signatory States with the ILO Convention No. 105 of 1957 on forced labour. Since ILO has never considered in its estimates of forced labor even the cases reported by CEACR, the article, starting from a possible generalization and application of the methods developed for the work at sea to the work on land, advances criticisms and revisions of the estimates of forced labour in the world produced by ILO.
\end{abstract}

* Doutorado em Sociologia dei fenomeni territoriali e internazionali pela Università di Trieste. Pesquisador universitário e professor da Università degli Studi di Padova. E-mail: valter.zanin@unipd.it. 
trabalho no mar e da sua aplicação para o trabalho forçado em terra, avança algumas críticas e revisões das estimativas do trabalho forçado no mundo produzidas pela OIT.

PALAVRAS CHAVES: Trabalho forçado e degradante. Marinha mercante internacional. Formas e estimativas do trabalho forçado no mar. Comparação com as estimativas da OIT sobre o trabalho forçado.
KEYWORDS: Forced and degrading labour. International seafaring sector. Forms and estimates of forced labour at sea. Comparison with the ILO's estimates on forced labour.

SUMÁRIO: 1 . ASPECTOS ORGANIZATIVOS DO TRABALHO MARÍTIMO E OTRABALHO FORÇADO.2. CONFINAMENTO A BORDO E IMPOSIÇÃO DE HORAS DE TRABALHO EXTRA NÃO PAGAS. 3. OS CÓDIGOS DA MARINHA MERCANTE COMO DISPOSITIVOS DE TRABALHO FORÇADO. 4. DESCONTOS INSTITUCIONAIS DO SALÁRIO E LISTAS NEGRAS. 5. CONCLUSÕES

\section{ASPECTOS ORGANIZATIVOS DO TRABALHO MARÍTIMO E O TRABALHO FORÇADO}

Nos estudos sobre o trabalho forçado e escravo contemporâneo emerge uma clara correlação entre trabalho forçado e escravo contemporâneo, de um lado, e alguns aspectos característicos ${ }^{1}$, do outro. O trabalho forçado e o trabalho escravo contemporâneo resultam difundidos principalmente em setores não-produtivos (como o trabalho doméstico, os serviços sexuais, os serviços militares ou de apoio às atividades militares), ou em setores não estratégicos ou ainda nas fases pré-produtivas voltadas ao preparo das condições objetivas do trabalho ${ }^{2}$; de qualquer forma, estão difundidos de maneira distintamente prevalente nos setores e fases de atividade caracterizados por uma baixa intensidade de capital; finalmente, estas formas de trabalho parecem reproduzir-se e difundir-se principalmente em derrogação dos Estados nacionais, em contravenção de suas legislações sociais e trabalhistas.

Se é inegável que essas correlações existem, tem-se que preguntar-se se elas fotografam o panorama global do trabalho forçado e escravo contemporâneo: há exceções a essas correlações? Onde e como se desenvolvem essas exce-

1 Por motivos de espaço, as referências bibliográficas deste artigo estão reduzidas ao mínimo.

2 Para os fins desta discussão, estratégico é um sector não substituível a médio e longo prazo; para produtivo entende-se setor produtivo de meios de produção ou de bens de subsistência mercadorias, como resultados, produtos, de uma transformação material; as condições objetivas de trabalho são meios de trabalho em um sentido amplo, os quais não entram no processo de trabalho imediato, mas sem os quais este processo não pode realizar-se ou só pode realizar-se de maneira incompleta - por exemplo, condições objetivas de trabalho são edifícios utilizados como fábricas, canais, ruas, queima e limpeza da floresta para criar pastagens. 
ções? Qual peso elas têm na massa total de trabalho forçado? E essas exceções são meras anomalias locais ou setoriais, ou sinalizam a existência de universos ou níveis de trabalho forçado ainda não devidamente compreendidos como tais? O trabalho forçado contemporâneo se desenvolve realmente em derrogação do Estado e da sua legislação? Neste artigo, tento enfrentar estas questões a partir da análise do caso do transporte marítimo internacional, em particular do transporte de bens materiais.

O transporte marítimo é diferenciado em seu interior por transporte de mercadorias e por transporte de passageiros (e indústria cruzeira), e difere também por navegação de cabotagem e navegação em águas internacionais. Estas diferenças são refletidas em condições e organizações de trabalho parcialmente diferenciadas. A grande maioria do pessoal a bordo de navios cruzeiros e passageiros não é composta de marítimos em sentido estrito, ou seja, de pessoal que atende à movimentação do navio, mas de pessoal que fornece serviços para os passageiros ${ }^{3}$.

Também a diferença entre cabotagem e navegação em águas internacionais, tem repercussões sobre as condições de trabalho: os trabalhadores marítimos empregados na cabotagem têm períodos de trabalho no mar - e, portanto, em isolamento - bem inferiores em comparação a aqueles empregados em águas internacionais; os primeiros têm contratos de trabalho mais prolongados, que não devem ser renovados a cada embarque, e são protegidos ou organizados pelos sindicatos em uma medida muito maior do que os marítimos empregados em águas internacionais.

Além destas diferenciações, o setor de transporte é caracterizado por uma intensidade de capital muito alta. Por exemplo, um navio petroleiro da classe very large crude carrier custa entre 70 e 75 milhões de euros e pode transportar mais de 200.000 toneladas de produtos petrolíferos e um navio graneleiro pode

3 Neste artigo, "trabalhadores marítimos" são entendidos confrome a definição contida nos relatórios elaborados a cada cinco anos pelo Istitute for Employment Reserch (IER) da Universidade de Warwick, por conta do Baltic and International Maritime Council (BIMCO) e da International Shipping Federation (ISF), ou seja:

- oficiais possuindo uma cédula de marítimo e certificados reconhecidos pelos critérios da International Convention on Standards of Training, Certification and Watchkeeping for Seafarers (SCTW) [Convenção Internacional sobre normas de formação, certificação e serviço de quartos para Marítimos (SCTW), 1978 e 1995, da IMO (International Maritime Organization);

- marinheiros possuindo uma cédula de marítimo ou de um documento de identificação que os certifique idôneos para ser empregados a bordo de navios superiores as 100 toneladas de arqueação na frota mercante mundial.

Essa definição também inclui aprendizes e cadetes, médicos de bordo e responsaveis do departamento de mesa (catering), mas não inclui os marítimos empregados em navios pesqueiros, rebocadores, embarcações que navegam em rios ou perto das costas, nem o pessoal empregado em postos de serviço, como é o caso dos navios cruzeiros ou passageiros, tais como os funcionários do hotel (BIMCO/ISF, 2005, p. 70). 
transportar uma carga de grãos suficientes para alimentar 1 milhão de pessoas por mais de dois meses, ambos tendo uma tripulação de somente 10-15 pessoas.

O transporte marítimo de mercadorias é um sector estratégico. A UNCTAD (United Nations Conference on Trade and Development) estima que em 2017 mais do $80 \%$ do volume (tonelagem) e mais do $70 \%$ do valor total do comércio mundial foram transportados por mar $^{4}$. Estima-se que uma paralisia do transporte marítimo levaria em dois dias ao colapso do sistema industrial mundial, e sendo que não menos de $25 \%$ das matérias-primas e dos produtos que compõem a alimentação humana básica no planeta é transportado pelo mar, a conseqüência seria também o começo da fome por uma grande parte da humanidade no prazo de poucos dias.

Além de estratégico, o transporte marítimo de mercadorias é um setor produtivo, desde que a parte absolutamente predominante da carga transportada é composta por matérias-primas e produtos intermediários, ou seja: o transporte marítimo realiza a função do deslocamento dos bens em produçao através de várias estações de trabalho localizadas em pontos espacialmente diferentes de montagem ou de transformação ao longo das cadeias produtivas internacionalizadas.

São apenas cerca de 650.000 marítimos que, ao longo de um único ano, transportam estes produtos essenciais para a reprodução das atividades industriais e para a sobrevivência das populações. A força de trabalho marítima global realmente a bordo durante o ano, incluindo o transporte de passageiros, navios de cruzeiro e outros tipos, é cerca de 800.000, enquanto o da força de trabalho global marítima disponível no mundo é de aproximadamente 1,2 milhões trabalhadores.

Vão mencionadas outras especificidades do trabalho marítimo. Do ponto de vista operacional, o trabalho marítimo atua por ampla parte em águas internacionais e põe regularmente os trabalhadores em portos e países estrangeiros. Do ponto de vista da organização do trabalho, o trabalho marítimo aparece também altamente internacionalizado e multinacionalizado: nos últimos 25 anos ao redor de $70 \%$ da força de trabalho marítima é internacionalizada ${ }^{5}$, desde que trabalha a bordo dos navios que arvoram bandeiras terceiras, diferentes daquelas do país de origem deles e por conta de proprietários que normalmente têm uma cidadania diferente daquelas dos trabalhadores e daquelas do registro do navio; uma elevada percentagem - mais difícil de estimar - é composta de

4 Em 2016, foram transportados por mar 10 bilhões e 287 milhões (10.287.000.000) de toneladas de mercadorias $(1,838$ bilhões de toneladas de petróleo bruto, 1.218 toneladas de derivados do petróleo e gás, 1,410 bilhões de toneladas de ferro, 1,140 bilhões de toneladas de carvão, 476 milhões de toneladas de grãos, 116 milhões de toneladas de bauxita/alumina/ alumínio, 30 milhões de toneladas de rocha fosfática).

5 Ver: ZANIN, 2007, pp. 174-183. Para entender: é como dizer que 70\% dos trabalhadores da indústria em terra no mundo fosse representado por imigrantes internacionais. 
trabalhadores que têm ou tiveram a experiência de trabalhar em tripulações multinacionais ${ }^{6}$.

Além disso, o trabalho marítimo atua em grande parte em isolamento - isolamento que foi enormemente aumentando nos últimos trinta anos. Os contratos de trabalho têm uma duração média de 4 meses para os marítimos de países da OCDE e de 9 meses para os marítimos da Ásia e da Europa Oriental, que compõem a grande maioria da força de trabalho marítima global. Durante a navegação, o navio é o lugar onde os trabalhadores executam suas tarefas, mas também onde estão alojados, comem e gastam seu tempo livre - tanto que muitos especialistas do transporte marítimo, apesar de sujeitar o conceito a verificações e correções, discutiram e discutem o navio e o trabalho marítimo em termos de instituição total. Enquanto navegam, os marítimos estão confinados a bordo e normalmente não têm como se comunicar com a família ou com os amigos.

Ao mesmo tempo, o tempo de permanência nos portos para operações de embarque e desembarque foi drasticamente reduzindo-se: nos últimos vinte anos esse tempo tem se contraído para dois-três dias para navios graneleiros e para 12-15 horas para navios porta-contêineres - ao mesmo tempo os portos foram progressivamente deslocados a maior distância dos centros urbanos, diminuindo as chances de socialização dos marítimos e aumentando sua invisibilidade social.

Também a bordo as possibilidades de socialização foram reduzindo-se, desde que de meados da década de 1960 para navios de tonelagem equivalente se passou de tripulações de 35-40 pessoas para tripulações de 15-20 pessoas. As transformações tecnológicas tiveram sua importância, mas as cargas de trabalho têm aumentado. Além disso, enquanto navegando os marítimos não podem suspender as atividades se não arriscando suas vidas e aquelas de seus colegas ${ }^{7}$. Por outro lado, os salários médios no setor marítimo são relativamente elevados, chegando hoje a superar mesmo por cinco vezes o salário médio na terra para algumas nacionalidades dos marítimos asiáticos.

Dada a elevadessima intensidade de capital, a importância estratégica, o elevado nível de internacionalização, o setor marítimo é altamente regulamentado do ponto de vista normativo. Não apenas o direito do trabalho marítimo tem antecipado de séculos o desenvolvimento do direito do trabalho para categorias homogêneas de trabalhadores; não apenas cada império e Estado moder-

6 Tem que lembrar que a partir do século XVI, as tripulações das maiores frotas mercantes nunca foram compostas com menos de $20 \%$ de estrangeiros; tal percentagem se aproxima e ultrapassa os 50\% desde a década de 1960 (ZANIN, 2007, pp. 77-87, 101-105, 116-117, 210-212).

7 O transporte marítimo é o trabalho mais perigoso do mundo depois da pesca. É complicado calcular o número de mortes por trabalho no mar, no entanto, por exemplo, em um país avançado como Dinamarca, o número de mortos no setor dos transportes marítimos é 11 vezes maior do que aquele no conjunto dos trabalhos em terra naquele país. 
no e contemporâneo tem possuído e possuem códigos específicos que regulam o trabalho marítimo - mas este último é altamente regulamentado também pelo direito internacional. Por exemplo, das 189 convenções internacionais da OIT, bem 41 tratam especificamente do trabalho marítimo: nenhuma outra categoria de trabalhadores fica nem de perto como alvo de tantas medidas.

Como pode-se constatar nesta breve descrição do trabalho marítimo contemporâneo, não parecem estar presentes no setor os elementos contextuais típicos que, de acordo com a maioria de estudos, caracterizam o trabalho forçado e escravo contemporâneo. E de fato, em 2002, um documento da OIT, dedicado à análise do trabalho marítimo, argumentou que:

o trabalho forçado ou compulsório não parece ser um problema particularmente relevante na indústria marítima, embora haja casos de confisco dos documentos dos trabalhadores e as horas extras sejam obrigatórias, atividades que podem envolver elementos de trabalho forçado. A liberdade de circulação e a mobilidade do trabalho marítimo são aspectos fundamentais a este respeito. Os marítimos, por exemplo, podem desfrutar da liberdade para ir à terra quando eles estão nos portos ${ }^{8}$.

Mas, apesar desta afirmação da OIT, quanto é relevante o problema do trabalho forçado no setor marítimo, mesmo admitindo que não seja "particularmente relevante" ? O documento citado não oferece estimativas. A primera - e até o momento única - tentativa em escala internacional de elaborar uma metodologia e uma estimativa mínima do número dos trabalhadores forçados no setor da marinha mercante internacional é meu livro I Forzati del mare ${ }^{9}$, onde eu tinha elaborado uma estimativa mínima de 141.113 trabalhadores forçados no mar, que representavam o $12,1 \%$ da força de trabalho marítima disponível no mundo em $2005^{10}$. Além disso, em I forzati del mare, eu propus uma segunda

$8 \quad$ ILO, 2002, pp. 3-4.

9 ZANIN, 2007. Somente em 2009, pela primeira vez, no seu relatório, o Diretor-Geral da OIT reconheceu a gravidade do problema no setor marítimo, fazendo referência explícita ao livro precedente: "Il apparaît de plus en plus que les marins et les pêcheurs sont particuliérement exposés au risque de travail forcé et de traite. Un ouvrage publié en décembre 2007 en Italie (V. Zanin: I Forzati del Mare, Rome, Carocci editore, 2007) est consacré aux «travailleurs forcés de la mer» et plus précisément à des groupes vulnérables dont la situation n'a jamais systématiquement attiré l'attention" ILO, 2009, 30. Apesar deste tardio reconhecimento da problematica condição dos marinheiros, não consta ter aumentado em seguida a atenção internacional sobre o assunto.

10 Este cálculo, como os outros neste artigo, a não ser diferentemente especificado, são efetuados sobre os dados da força de trabalho marítima mundial estimados nos relatórios quinquenais elaborados pelo IER po conta do BIMCO/ISF.

A estimativa mínima da OIT em 2005 era de 12,3 milhões de trabalhadores forçados no mundo (BELSER, DE COCK, MEHRAN, 2005), ou seja o 0,4\% da população economicamente ativa empregada no mundo. Se temos por válidos estes dados, o trabalho forçado não parece ser um problema particularmente relevante também para o conjunto total dos trabalhadores, tanto que eles trabalhem em terra ou no mar. Para evitar mal-entendidos: 12 milhões de pessoas em condições de trabalho forçado podem ser relativamente poucas, mas aqueles doze ou 
estimativa - não mínima, mas sempre conservadora, que, na minha opinião, era muito mais próxima da realidade - de 392.000 marinheiros em condições de trabalho forçado, equivalentes ao $33,5 \%$ da força de trabalho marítima disponível em 2005. Neste artigo, explicito categorias e as estimativas subjacentes a este segundo resultado - e quando for o caso revisando-as - e elaboro e exponho também estimativas para o 2010 e 2015, tendo em perspectiva a comparação com os relatórios da OIT sobre trabalho forçado de 2005, 2012 e de 2017.

\section{CONFINAMENTO A BORDO E IMPOSIÇÃO DE HORAS DE TRA- BALHO EXTRA NÃO PAGAS}

Começamos analisando o caso que é mencionado no documento ILO acima: aquele da liberdade para descer à terra nos portos de chegada.

Em resposta aos eventos de 11 de setembro de 2001, em 2002 foi criado o International Ship and Port Facility Security Code (ISPS), oficialmente entrado em vigor em 2004. Em 2007 a International Transport Federation (ITF) publicou os resultados de um questionário sobre o impacto da introdução do ISPS, que os membros do ITF avaliam refletir as opiniões de cerca de 165.000 marítimos em todo o mundo. $86 \%$ dos entrevistados disse que a introdução do ISPS conduziu a um aumento nas cargas de trabalho, sem correspondente incremento de pessoal e sem aumentos salariais, comportando em média de sete a oito horas de trabalho extra não remunerado por mês, para tarefas anteriormente não previstas pelos contratos e geralmente nunca antes realizada pelos marítimos - como fazer segurança nas passarelas dos navios, enquanto estes estão atracados firmemente nos portos ${ }^{11}$.

Na guerra entre terroristas, inaugurada em 2001, os marítimos são o grupo de trabalhadores que em absoluto sofreu as maiores restrições entre todos os trabalhadores de todos os outros setores do mundo: enquanto vai exigindo-se que os marítimos desempenhem o papel de guardas de segurança, ao mesmo tempo eles são tratados como potenciais terroristas, tanto que em algumas partes do mundo, os marítimos estão sujeitos a restrições que constituem casos de violação dos direitos humanos. O 70\% dos entrevistados pelo ITF afirmou de ter sofrido proibição da permissão de descer à terra após a introdução do ISPS, especialmente nos portos dos Estados Unidos, mas também em alguns portos no norte da Europa e de outros países. Um marítimo disse: “os marítimos têm medo de adoecer em portos americanos e, tendo de recorrer a tratamento médico, de vir negada a permissão para deixar o navio" ${ }^{12}$.

mais milhões de pessoas vivem essa condição na sua pele. E, lembramos que este é o número mínimo, sendo que OIT não fornece indicações sobre os màximos possiveis. Tenho discutido em detalhe em outra ocasião estes problemas, na esperança de ter mostrado que o número de trabalhadores forçados na realidade é infelizmente muito mais alto (ZANIN, 2017).

11 ITF, 2007.

12 Ibid., p. 7. 
No âmbito destas políticas, os EUA exigem dos marítimos o visto consular para descer nos portos estadunidenses. De acordo com as convenções internacionais que codificam práticas marinheiras velhas de séculos, os membros das tripulações não necessitam de vistos para poder descer temporariamente a terra nos portos. A mesma Convenção n. 108 de 1958 da OIT (C108 Seafarers' Identity Documents, 1958), no art. 6, especifica que os marítimos não precisam de ter um visto para ser autorizados a descer à terra ${ }^{13}$. Além disso, os funcionários do controle da imigração podem conceder ou negar permissão para descer à terra, a seu critério. Em alguns portos dos EUA são até os operadores de terminais que proíbem os marítimos estrangeiros de passar através dos terminais ou exigem custos exorbitantes para escoltar tripulações ou capelães e sindicalistas através dos terminais. Sempre nos EUA, algumas companhias têm sido pedidas de contratar guardas armados para impedir aos marítimos estrangeiros de descer de seus navios.

Para entender o efeito da proibição de descer à terra, lembramos que os marítimos que trabalham nas rotas oceânicas têm ficado a bordo, ou seja no lugar onde trabalham e devem viver, vários dias, se não semanas. A oportunidade de descer à terra, depois ter executado um serviço estratégico para a indústria e o comércio internacionais - e, ao chegar a um porto dos EUA, para a indústria e o comércio dos EUA - é uma concessão mínima, se não um direito, como deveria ser, para estes trabalhadores: forçá-los ainda a ficar a bordo durante todo o tempo de estadia nos portos, constitui uma pena adicional para um trabalho que já é difícil, e que vê os marítimos longe de casa e isolados das possibilidades de socialização das quais qualquer trabalhador a terra normalmente goza, a menos que não se trate de um trabalhador na prisão ou condenado aos trabalhos forçados.

Um efeito colateral dessas políticas é a redução das possibilidades de contato dos marítimos com suas organizações de assistência, os capelães dos portos e os sindicatos, tornando-se mais complicado denunciar situações de trabalho degradantes e faltas de pagamentos (então de formas de trabalho forçado); portanto tais políticas de controle constituem um elemento de perpetuação de possíveis casos de trabalho forçado.

13 A dificuldade para muitos marítimos é representada pelo tempo necessário para obter um visto. Em alguns casos este tempo é maior do que aquele que intercorre entre a assinatura do contrato e à entrada em serviço a bordo: para os filipinos, por exemplo, o tempo de espera médio para obter um visto é de dois a três meses. Além disso, muitos marítimos encontram problemas logísticos para obter o visto, porque eles trabalham com contratos de dez a doze meses, com apenas um ou dois meses intervalo entre um contrato e outro. Finalmente, às vezes os marítimos não podem obter vistos porque não existem consulados no último porto estrangeiro visitado ou porque o navio recebe a ordem para dirigir-se a portos dos Estados Unidos, enquanto já está navegando. O inquérito revelou também que marítimos de algumas nacionalidades encontram mais dificuldades em conseguir um visto para os EUA, em particular aqueles do Vietnam, da China e do Oriente Médio. 
Para calcular o número mínimo de trabalhadores sujeitos a esta forma de confinamento forçado no local de trabalho e ao suplemento de trabalho não remunerado para as atividades de vigiamento, deve-se considerar o número de marítimos que chegam nos portos onde tais disposições são aplicadas, mas podemos avançar sem exagero a estimativa que pelos menos um terço dos marítimos embarcados em navios de carga em rotas oceânicas se encontram nessa condição ${ }^{14}$. Ficamos frente se não de uma negação, pelo menos de uma minimização ou remoção da questão por parte dos especialistas da OIT.

\section{OS CÓDIGOS DA MARINHA MERCANTE COMO DISPOSITIVOS DE TRABALHO FORÇADO}

Temos que sublinhar uma atitude paradoxal da OIT para os problemas do trabalho forçado no setor marítimo. A este respeito, existem precedentes históricos, desde que enquanto a escravidão e os caráteres mais detestáveis dos sistemas de trabalho forçado eram parcialmente combatidos a terra, eles se reproduziam no mar não somente na quase total indiferença, mas mesmo sendo tomados como exemplo por aqueles que apoiavam a necessidade de sanções disciplinarias do trabalho colonial, sem que esse paralelo levasse à imediata inclusão das modalidades de sujeição do trabalho marítimo na ordem do dia do abolicionismo e da luta contra o trabalho forçado.

Por exemplo, em 1929, na conferência organizada pela OIT em Genebra, dedicada aos trabalhos preparatórios da Convenção n. 29 sobre o trabalho forçado, Schumann, o representante holandês na OIT, contestou “a objeção dogmática que a observância dos contratos civis não possa ser sujeita a disposição do código penal. Não seria este o único exemplo na história e na prática do direito: pense-se em outro contrato de trabalho com sanções, universalmente conhecido e aplicado, o contrato de arrolamento da tripulação da marinha mercante" 15 .

O problema é que essas leis e regulamentos não são limitados há décadas, de 1920 ou de 1930, mas perduram, por alguns países, até hoje. Ao analisar os

14 No início da decada de 2000, a bordo dos navios de carga acima das 1000 toneladas que operavam no mundo prestavam serviço ativo aproximadamente 650.000 marinheiros (LANE et al., 2002, p. 1); em 2003, o Ministério da Transporte dos EUA publicou um estudo sobre as tripulações de navios de carga chegadas em oito grandes portos dos EUA: Houston, Nova Orleans, Los Angeles/Long Beach, Newarck, New York, Miami, Savannah, Seattle. Nestes oito portos, os marítimos estrangeiros resultantes da pesquisa foram 222.865 , a maioria pertencentes a nacionalidades consideradas a risco de contágio terroristico ou potenciais inimigos dos Estados Unidos: filipinos, indonésios, chineses (US DEPARTMENT OF TRANSPORTATION-Maritime Administration, 2003). Se podemos considerar que parte destes marítimos foi cadastrada em mais de um desses portos, fazendo, portanto, contrair o seu número efetivo, por outro lado, essa avaliação deve ser compensada à luz do fato de que as restriçôes não são limitadas apenas aos portos dos EUA (que obviamente são mais numerosos dos oito pesquisados), mas também vigem em numerosos portos europeus e de outros países.

15 MONDAINI, CABRINI, 1931, pp. 157-158. 
relatórios anuais do Committee of Experts on the Application of Conventions and Recommendations (CEACR) ${ }^{16} \mathrm{da}$ OIT, pode-se constatar que apenas desde 1963 começou um levantamento sistemático da adaptação dos códigos de navegação dos Países que assinaram a Convenção OIT n. 105, adoptada em 1957 (C105 Abolition of Forced Labour, 1957) ${ }^{17}$, que especificava que o trabalho forçado nunca poderia ser usado para fins de desenvolvimento econômico ou como um instrumento de educação política, de discriminação, de disciplina do trabalho ou como punição por ter participado em greves.

Embora todos os Estados-membros sejam obrigados a cumprir com as oito convenções fundamentais da OIT (incluindo as duas sobre o trabalho forçado, n. 29 de 1930 e n. 105, de 1957), CEACR analisa os relatórios dos governos e as correspondentes leis somente depois que o Estado-membro tem ratificado a Convenção de referência, embora essa possa ser uma das oito fundamentais. De fato, além dessa, da análise dos relatórios anuais do CEACR emergem algumas outras deficiências: nem sempre os governos apresentam os relatórios trienais; nem sempre o CEACR detecta as normas que configuram o caso de trabalho forçado para os marítimos, desde que o país ratificou a Convenção n. 105 (às vezes, a detecção ocorre muitos anos depois da ratificação, enquanto resulta que as normas denunciadas têm sido em vigor a muito tempo antes e depois que a convenção tivesse sido ratificada).

Os dois tipos mais comuns de denúncia de normas que regulam o trabalho marítimo, enquanto contrárias à Convenção n. 105, são representados pelas normas que preveem a recondução forçada a bordo dos marinheiros que desertam o navio e pelas normas que prevem condenações penais (com obrigação de trabalho exigida pelas sentenças) para violações da disciplina que não poem em perigo a vida das pessoas a bordo e nem danificam bens materiais (navio e mercadorias transportadas). Menos frequentemente são relatados casos onde o exercício da greve pelos marítimos é punível penalmente (com penas que prevem o trabalho forçado).

16 O CEACR - Comitê de Especialistas sobre a Aplicação das Convenções e das Recomendações da OIT - foi criado em 1926 para examinar o número crescente de relatórios governamentais sobre as convenções ratificadas. Hoje consiste em 20 eminentes juristas, nomeados pelo Conselho de administração para um mandato de três anos. Os especialistas provêm de diferentes regiões geográficas, culturas e sistemas jurídicos. O papel do Comitê é aquele de fornecer uma avaliação imparcial e técnica do estado de aplicação das normas trabalhistas internacionais nos Estados membros da OIT. A cada três anos, os governos devem apresentar relatórios sobre as medidas tomadas para aplicar as oito convenções fundamentais (incluindo as duas sobre o trabalho forçado) que eles podem ter ratificado; para todas as outras convenções, os relatórios devem ser apresentados a cada cinco anos. Os relatórios do CEACR são publicados anualmente, a partir 1932.

17 Escrevendo I Forzati del mare, eu tive à disposição apenas um relatório completo do CEACR. $\mathrm{Na}$ elaboração deste artigo, eu pude dispor da série completa de relatórios anuais CEACR desde 1932 para 2017. 
No que diz respeito às normas de recondução forçada a bordo dos desertores ${ }^{18}$, deve-se considerar que, também se as normas previstas não são aplicadas por algum tempo, como em 2001 alegava o governo tailandês em resposta aos inquéritos da OIT (embora "por algum tempo" se entendia neste caso somente desde "uma década"), suas ativação, como sempre, depende das circunstâncias, não faltando o sinal de contratendência: após o 2001, o governo do Bangladesh, perante o fenómeno das deserções de marítimos nacionais em portos estrangeiros, pensa em introduzir penas mais duras para os desertores, prevendo suas prisão e suas obrigação ao trabalho quando repatriados.

Os casos denuciados pelo CEACR em referência a sanções por greves no setor marítimo, são muito poucos, mas estes incluem aqueles de duas grandes nações marítimas: Grã-Bretanha e Grécia.

O novo Merchant Shipping Act britânico, que entrou em vigor em 1995, prevê (art. 59.1) condenas até dois anos de prisão (com obrigação de trabalho), ou uma multa ou ambas para o trabalhador marítimo, que se acorde com outros colegas, enquanto o navio está no mar, para transgredir as ordens legítimas, negligenciando o trabalho ou impedir a continuação da viagem ou da navegação. Estas sanções podem igualmente ser aplicadas aos marítimos que têm contenciosos sindicais em curso ou sejam em greve. Sempre na Grã-Bretanha, desde 1999, entrou em vigor a lei sobre as relações industriais - Employment Relations Act (ERA) -, que finalmente reconheceu alguns direitos fundamentais dos trabalhadores que tinham sido negados durante décadas, garantindo aos trabalhadores de formar ou de participar de sindicatos de sua escolha, embora ainda impondo restrições sobre o direito à greve, proibindo os piquetes e tornando civilmente responsáveis os participantes a greves de solidariedade. No entanto, os trabalhadores marítimos são excluídos das disposições legislativas desta lei de 1999 no caso que os navios em que trabalham sejam registrados sob bandeiras estrangeiras ${ }^{19}$, se eles não residem normalmente na Grã-Bretanha ou se seu trabalho é feito... fora o Grã-Bretanha!

No que diz respeito à Grécia, o CEACR chama a atenção para alguns artigos da lei de 26 de junho de 1944, n. 3267, relativas à negociação coletiva da marinha mercante (artigo 4.1), e da lei de 25 de outubro de 1936, n. 299, sobre os contenciosos trabalhistas no setor marítimo (artigo 15), em virtude dos quais a violação de uma disposição de um contrato coletivo ou de uma ordem de execução sobre os salários pode ser punida por aprisionamento e com corres-

18 Se não fica claro, é como se um operário de fábrica de terra decidesse que ele não agüenta mais o local de trabalho e isse embora, para ser parado e ser recondizido na fábrica para trabalhar; com a diferença que o navio, enquanto navegando, é isolado e que o trabalhador, mesmo que quisesse, não poderia descer e não trabalhar.

19 Lembramos que nos anos de 1990 até hoje por volta de mais do $70 \%$ da frota mercante mundial é registrado sob bandeiras de conveniência, ou seja, terceiras, estrangeiras. 
pondente trabalho forçado. Em 1999, o Ministério da marinha mercante grego propõe de limitar a aplicação de algumas normas, passiveis de acusas de trabalho forçado (Code of Public Maritime Law de 1973, artigos 205, 208, 207.1, 210.1, 222; lei 3276/1944, artigo 4.1; lei 229/1936, artigo 15), aos casos em que haja: a) danos do navio ou da carga, das pessoas a bordo, de um indivíduo ou da sua propriedade emquanto no mar; c) perturbação da ordem pública, da segurança nacional, da saúde ou da pública moral. O CEACR especifica que o dano para a carga ou outros bens pode ser punível apenas em casos de atos dolosos e não em caso de danos causados por mera negligência, e pergunta de esclarecer o que o governo entende por "ordem pública" e "pública moral”. Em seguida da reação governativa à greve marítima de setembro de 2002, os sindicatos marítimos gregos denunciaram na OIT o próprio governo de recorrer ao trabalho forçado contra a grevistas, exumando um decreto presidencial de 1974, que previa a declaração do "estado de emergência" em caso de "interferência com a vida econômica do país”.

A abordagem para o problema do trabalho forçado no mar por OIT é contraditória: enquanto o CEACR detecta e denuncia normas que constituem baluartes legais de trabalho forçado no setor marítimo, os relatórios da OIT sobre fomas e estimativas do trabalho forçado até hoje nunca mencionam o caso dos marítimos.

Para ter um termo de comparação, vamos nos concentrar nos mesmos períodos analisados nos relatórios da OIT dedicados as estimativas e as formas do trabalho forçado no mundo de 2005 e 2017 . No primerio relatório, o período analisado é aquele de 1995-2002. Neste período os países denunciados do CEACR por terem leis da marinha mercante em contraste com a Conv. n. 105 (1957) e que ainda mantinham essas normas em 2005, eram $29^{20}$ e os marítimos pertencentes a estas nacionalidades representavam $20,5 \%$ da força de trabalho marítima mundial disponível em 2005.

Desde que não estão disponíveis dados sobre a força de trabalho marítima mundial para 2017 (ano de publicação do segundo relatório da OIT aqui mencionado, que estima os casos de trabalho forçado em 2016), mas para 2015, tenho analisado os relatórios CEACR de 2014 e 2015. Nesses dois anos os países relatados para manter leis laborais marítimas que configuravam mecanismos de trabalho forçado eram $23^{21}$ e os marinheiros pertencentes a estas nacionalidades representavam 5,2\% força marítima mundial disponível em 2015.

20 Estes 29 países são os seguentes: Bahamas, Bangladesh, Bélgica, Belize, Benin, Camarões, Canadá, Equador, Egito, Fiji, Gabão, Gana, Grécia, Irlanda, Jamaica, Quênia, Kuwait, Libéria, Malásia, Ilhas Maurício, Nigéria, Paquistão, Papua-Nova Guiné, Senegal, Tanzânia, Tailândia, Trinidad e Tobago, Turquia, Reino Unido.

21 Estes 23 países são os seguentes: Angola, Bahamas, Bangladesh, Belize, Benin, Camarões, Egito, Gana, Grécia, Jamaica, Quênia, Kuwait, Libéria, Ilhas Maurício, Nigéria, Papua-Nova Guiné, Paquistão, Senegal (2017), Tanzânia, Seychelles, África do Sul, Trinidad e Tobago, Turquia. 
Lembro que estas estimativas consideram apenas os países que ratificaram a Convenção n. 105 (1957) da OIT e apenas pelas leis denunciadas pelo CEACR em quanto fazem explícita referência aos marítimos ${ }^{22}$; se levássemos em conta os países que expressam uma força de trabalho marítima e que foram denunciados pelo CEACR por causa de leis contrariando a Convenção n. 105, as quais se dirigem para todos os trabalhadores daqueles países, por tanto incluindo os marítimos, as percentagens do trabalho forçado marítimo obviamente aumentariam: no caso de 2015, a percentagem de trabalhadores marítimos embridados nesses sistemas jurídicos subiria para $27,3 \%$ da força marítima mundial disponível naquele $\mathrm{ano}^{23}$.

\section{DESCONTOS INSTITUCIONAIS DO SALÁRIO E LISTAS NEGRAS}

Existem outros meios pelos quais os Estados promovem o trabalho forçado no setor marítimo. O emprego de marítimos nacionais em navios estrangeiros representa uma verdadeira indústria de estado para algumas das maiores nações fornecedoras de trabalho marítimo a nivel mundial ${ }^{24}$. Isto é, por exemplo, o caso das Filipinas, da República Popular da China e do Myanmar.

As Filipinas são o maior fornecedor do mundo de força de trabalho marítimo para navios estrangeiros. A estrutura de fornecimento de marítimos filipinos, embora com algumas modificações, é aquela estabelecida com o National Seamen's Board (NSB), em concomitância com o desbruçamento em escala de massa dos marítimos filipinos no cenário mundial, em 1974, ou seja, dois anos após a suspensão de garantias constitucionais e a introdução da lei marcial nas Filipinas pelo Presidente Ferdinand $\operatorname{Marcos}^{25}$.

22 De fato, leis previndo a recondução forçada a bordo e sanções penais com prisão e trabalho forçado para violações da disciplina se encontram também nos códigos de navegação Estados-membros da OIT que não ratificaram a Convenção n. 105 (1957) e, portanto, não são examinados pelo CEACR. Isto é, por exemplo, o caso do Merchant Shipping Act do Mynamar (Birmânia), só para nomear um Estado que expressa uma significativa força de trabalho marítima à escala internacional.

23 Os Estados em questão são: Argélia, Azerbaijão, Camboja, China (Hong Kong), Eritreia, Etiópia, Fiji, Filipinas, Rússia, Sri Lanka, Síria, Turcomenistão, Venezuela.

24 Por exemplo, Margtas Amante estimou que, em 2003, as remessas de cerca de 100.000 marítimo filipinos foram em torno de 2 bilhões de dólares, ou seja cerca de $31 \%$ do total das remessas dos 4.200.000 trabalhadores filipinos no exetrior e cerca de $6 \%$ do valor total das exportações filipinas (AMANTE, 2003, p. 1).

25 Anos depois do fim da ditatura, em setembro de 2005, o Department of Labour and Employment (DOLE), ou seja, o Ministério do trabalho filipino, introduziu alterações ao código do trabalho. O novo código estabelece que se uma greve ocorre em um setor industrial "indispensavel para os interesses nacionais" é possível impor uma arbitragem obrigatória e constrigir os trabalhadores a retomar o trabalho e que a polícia e o exército podem intervir para executar essa decisão. A participação em greves declaradas ilegais prevê penas de prisão de até três anos, enquanto que para aqueles que organizam "meetings com o objetivo de difundir propaganda antigovernativa” é prevista a prisão perpétua ou a pena de morte. A ICFTU (International Confederation of Free Trade Unions) aponta que o termo meeting é usado como sinônimo para "piquetes" durante as greves. Diante de um crescente de protestos populares, o Presidente das 
O recrutamento dos marítimos filipinos para navios estrangeiros acontece através da mediação de agências de emprego, às quais o governo emite licença. Apesar de serem empresas privadas, o governo controla e cadastra o número de marítimos empregados em navios estrangeiros através do órgão governativo que supervisiona o trabalho dos migrantes filipinos no exterior: o Philippines Overseas Employment Administration (POEA). Os funcionários do POEA assinam os contratos estipulados, através das agências, pelos marítimos filipinos e o próprio formato do contrato de emprego marítimo é padronizado de acordo com as diretrizes do POEA.

O governo exerceu desde o começo um controle rigoroso sobre os salários dos marítimos, aos quais foi feita obrigação de remitir a parte dos salários pagos em dólares americanos. Em meados da década de 1980, a obrigação foi substituída por um termo contratual, ainda em vigor, que fixava em $80 \%$ dos salários base a cota que devia ser depositada em um banco filipino.

Por outro lado, não faltam exemplos de dívida voluntária sob a forma de adiantamentos sobre o salário (ou descontos no salário): nas Filipinas são, por vezes, as agências a exigir adiantamentos em dinheiro para encontrar trabalho, enquanto o governo até recentemente tem, na melhor das hipóteses, fechado os olhos para esta prática. Pagar, talvez ficando endívidados, para ter acesso ao emprego a bordo, ou saber que parte dos primeiros salários serão descontados pelos intermediadores, funcionam como poderosos fatores de inibição de solicitação de melhorias de condições de trabalho insatisfatórias e que em outras situações seriam abandonadas ${ }^{26}$.

Em 1996, a OIT revisou a Convenção n. 9 de 1920 sobre o recrutamento dos marítimos (C9 Placing of Seamen Convention, 1920), substituindo-a com a n. 179 (C179 Recruitment and Placement of Seafarers Convention, 1996). Na nova Convenção são explicitamente proibidos os adiantamentos em dinheiro (fees) para encontrar emprego a bordo e também explicitamente proibida é a prática das listas-negras (blacklisting), ou seja, a inscrição de nomes de marítimos em listas que vêm feitas circular entre agências e algumas companhias, avisando de não empregar o marítimo listado, muitas vezes designado como um encrenqueiro, sendo várias vezes a "encrenca" representada por pedidos do marítimo para os sindicatos intervirem para receber salários atrasados ou para adaptá-los aos mínimos internacionais, ou para denunciar situações degradan-

Filipinas, Gloria Arroyo, em 25 de fevereiro de 2006, declarou o estado de emergência, seguido por numerosas detenções de sindicalistas e opositores, garantindo a impunidade para violência e assassinatos de sindicalistas e líderes dos trabalhadores. Somente em 2005, 33 sindicalistas foram mortos e outros 130 agredidos, feridos ou torturados (ICFTU, 2007). A violência tem sido legitimada pelo Estado, declarando os sindicalistas "comunistas" e "inimigos do estado".

26 Os maiores centros de difusão das práticas hoje denunciadas de pedidos de adiantamentos por agentes e empresas de intermediação de trabalho marítimo são - além das Filipinas - Indonésia, China, Filipinas, Egito, países ribeirinhos do mar Negro. 
tes a bordo. Esta nova Convenção foi ratificada somente por onze nações, mas entre elas as Filipinas.

Apesar da ratificação da Convenção, a prática do blacklisting é esplhadada: a associação das vítimas filipinas de blacklisting - a Tining Marino - declara de organizar mais de 10.000 trabalhadores em tais condições: um número impressionante sobre uma população de aproximadamente 200.000 marítimos filipinos. Efetivamente a prática não é contrastada e, nas Filipinas, há até um sistema duplo de blacklisting: um privado, que mencionamos, e um governativo: o POEA cadastra em uma lista negra os nomes dos marítimos que foram condenados por violações da disciplina, aos quais é impedido de trabalhar em navios estrangeiros; além disso, o POEA mantém também uma assim chamada watchlist, na qual são cadastrados os nomes dos marítimos, cujos casos de infração disciplinar estão ainda sob exame. Embora ainda não - nem necessariamente - encontrados culpados, os trabalhadores cadastrados na watchlist enfretam as mesmas dificuldades para encontrar um emprego das pessoas incluídas na lista negra, desde que as agências governamentais se recusam a dar-lhes trabalho até os casos estão pendentes.

A China dispõe da maior reserva no mundo de marítimos certificados. No início de 1990, o Ministério do trabalho começou a desenvolver políticas de recrutamento de trabalhadores marítimos para navios e companhias de navegação estrangeiras. O Ministério do trabalho emite autorizações para agências, das quais exige depósitos de segurança, no montante de meio milhão de yuan. Entre o final da década de 1990 e o primeiro qüinqüênio de 2000, surgiram outras agências que obtiveram licenças semelhantes em troca de cauções pelos Ministérios da educação, das relações exteriores e da segurança pública e mais tarde fizeram sua primeira aparição também agências sem licença governativa. $\mathrm{O}$ efeito geral foi um aumento na concorrência intergovernamental e naquela entre as agências, causando uma compressão do custo do trabalho oferecido para o cliente estrangeiro.

Enquanto os custos do trabalho oferecido vão se comprimindo, os trabalhadores devem pagar a agência cerca de $25 \%$ do montante total do salário para taxas de serviço, não incluindo as despesas - sempre às custas do empregado - para exames médicos, formação, documentação (do passaporte as varias certificações). Além disso, o regulamento ministerial fixou uma cota de $20 \%$ sobre o montante do salário que os trabalhadores contratados são obrigados a pagar como depósito para as agências, a fim de assegurar o cumprimento das obrigações contratuais. A legislação prevê que a caução possa ser devolvida ao trabalhador se a agência e o cliente estrangeiro estão satisfeitos com o trabalho feito no exterior pelo trabalhador: regra voltada, portanto, especificamente para assegurar a disciplina do trabalho, independentemente de suas condições que podem ou não corresponder às expectativas do trabalhador ou as promessas 
de agências e clientes, sem mencionar que tal cláusula abre uma brecha para possíveis abusos e fraudes em dano dos trabalhadores.

Abusos e fraudes podem acontecer tanto mais facilmente emquanto as empresas estrangeiras não contatam diretamente os trabalhadores, porque os contratos geralmente intercorrem apenas entre as agências e as empresas estrangeiras e não entre o trabalhador e a empresa estrangeira, a qual, portanto, não tem nenhum acesso direto para a força de trabalho chinesa, nem os trabalhadores têm a oportunidade de ver os originais dos contratos estipulados entre a agência e os empregadores estrangeiros ${ }^{27}$. A falta de um encontro direto entre trabalhadores e os empregadores finais da força de trabalho permite às agências explorarem à sua vantagem os diferenciais entre custo do trabalho nos países de exportação e níveis saláriais médios na China, fazendo, no entanto, também parcialmente o jogo daquelas empresas estrangeiras que apontam para rebaixamento do custo do trabalho como fator competitivo. A prática do duplo contrato e da dupla folha de salário está então inscrita no sistema mesmo, permitindo de evadir dos salários mínimos fixados no setor marítimo pela OIT. ITF estima que os agentes chineses retêm cerca do $80 \%$ do salário pago aos marítimos pelas companhias de navegação. Além disso, Bin Wu calcula que entre 30 e $40 \%$ do salário recebido realmente pelos marítimos termina na conta das agências ${ }^{28}$.

Das entrevistas etnográficas que eu tinha conduzido em 2001 e 2005 no porto de Veneza com marítimos chineses, que trabalhavam em navios de carga arvorando bandeiras terceiras, soube que o salário base deles era integralmente e diretamente depositado em um banco na China. Traduzido em prática: se os marítimos queriam dispor de dinheiro, enquanto eles estavam em portos estrangeiros, tinham inevitavelmente de trabalhar horas extras. Estes trablhadores chineses eram muitas vezes relutantes e evasivos em falar quando se tocava a questão dos seus salários e, quando perguntados sobre o montante aproximado de seu salário, respondiam que era um "segredo". A este respeito, é esclarecedor o episódio do Arcadia, cujo caso tornou-se a ocasião de confrontação entre ITF, OIT e o governo chinês. Evidentemente, os marítimos chineses conheciam o fato ou tinham sido adequatamente instruidos a não fazer palavra de seus salários e condições de trabalho. Eis o que aconteceu.

Em março de 1991, uma agência de Tianjin tinha contratado onze marítimos chineses para trabalhar em um navio que arvorava bandeira do Panamá: o Arcadia. Durante os treze meses a bordo do Arcadia, os onze marítimos foram xingados regularmente pelos oficiais gregos e quase que diariamente alguém deles foi espancado. Para receber o salário básico tinham de trabalhar doze horas por dia, sem dia de descanso. A bordo do navio não havia medicamentos sufi-

27 WU, 2008, p. 24.
28 Ibid., p. 25 . 
cientes, nem o armador tinha segurado os marítimos chineses em caso de doença ou morte. Quando um dos marinheiros caiu doente, ele foi demitido e 30 dias de pagamento lhe foram retidas em conta das refeições. Após ter repetidamente procurado entrar em contato com a agência que os tinha contratados e tendo recibo somente uma vez resposta para manter a calma e não provocar os estrangeiros, ao chegaram no porto de Ravenna na Itália os marítimos contataram o inspetor da ITF. Os trabalhadores portuários se recusaram a descarregar o navio e a abastecê-lo de combustível e água, até que o problema não tivesse resolvido. Em seguida a essa intervenção, aos marítimos foram pagos dois meses de salário atrasado e fornecidos os medicamentos necessários, e o armador compelido a assinar um acordo para desembolsar a diferença entre os salários pagos e os mínimos previstos pela OIT, para um total de 95.000 dolares americanos. Ao retornar à China, em 19 de agosto de 1992, os marítimos foram presos pela polícia e acusados pela agência que os tinha contratados de ter "divulgado segredos de estado". Os 95.000 dolares obtidos foram confiscadas e os marítimos jogados na prisão. Aos marítimos foram retirados os documentos e seus nomes cadastrados em uma lista negra, tanto que, mesmo depois de sua libertação e absolvição de qualquer acusação, eles não encontraram mais trabalho.

No Myanmar, os marítimos birmanêses podem obter trabalho em navios estrangeiros somente através de uma agência de governo, a Seafarers Employment Control Division (SECD), que supervisiona os contratos de trabalho. Diferentemente dos filipinos, aos quais é pedido para depositar em bancos nacionais a maior parte do salário, que ainda é possuído por eles, mas que garante fluxos de caixa para o sistema econômico doméstico, o governo de Myanmar força os marítimos a remeter parte do salário, na quantidade de três meses de salário diretamente para o Estado ou às agencias reconhecidas. De fato, a cessação do contrato antes de ter recebido dinheiro expõe ao risco de ser sancionados pelo Estado birmâno.

O regime tem literalmente apavorado os marítimos, tanto para que eles não se sintam seguros mesmo quando a falta de dinheiro não depende deles: muitas vezes o governo se recusa a devolver os documentos até para aqueles marítimos birmanês que foram abandonados no exterior ou para naufrágio do navio ou para falência do armador, talvez à luz de uma interpretação em toda desvantagem dos marítimos de um termo, já por si ambíguo, presente nos contratos marítimos birmanêses, que prevee que eles envolve que "mantenham alta a dignidade do Estado". Enquanto aos marítimos vem feita injunção de manter alta a dignidade do Estado, muitas vezes os contratos preveem a assinatura de uma dupla libreta de paga a fim de evadir o salário mínimo internacional.

Sempre para preservar o alto nome do governo birmanês, os marítimos que encontram trabalho através da SECD são impelidos a de assinar um documento em que se comprometem a não entrar em contato com sindicatos no 
estrangeiro por nenhuma razão, e em particular com a ITF, e que, mesmo se o ITF ou outros sindicatos conseguem ganhar aumentos de salários ou obter salários atrasados devidos aos trabalhadores, tais quantias devem ser retornadas para o capitão do navio. Esta cláusula aplica-se não só à contencios salarias, mas também a queixas relativas às condições de vida a bordo e às tentativas de melhorá-los. O governo birmanês tem punido os marítimos que contactaram os sindicatos, revogando seus certificados marítimos e confiscando seus passaportes. Por outro lado, o governo birmanês não reconhece sindicato qualquer e cada atividade sindical independente é proibida.

Comentando o que precede, deve-se lembrar que a OIT, no seu relatório sobre trabalho forçado de 2001, ressaltava que a pena ameaçada "não precisa assumir a forma das sanções penais, mas pode pegar a forma da perda de direitos ou privilégios"29. Entre os privilégios, se queremos chamá-los assim, tem aquele de encontrar emprego em setores específicos da indústria, nos quais talvez os salários são mais elevados do que em outros e para ter acesso ao quais às vezes foram pagas quantias empenhadoras. O blacklisting e ainda mais o seqüestro (institucional) das cédulas de marítimos não visa o afastamento do trabalhador de uma única nave ou de uma única companhia, na qual houve a disputa: as listas negras circulam entre várias agências e companhias armadoriais, reduzindo drasticamente as chances do trabalhador encontrar emprego; no caso da retirada da cédula de marítimo, o setor está completamente fechado para o trabalhador. A prática do blacklisting não é limitada as Filipinas e à China, mas é difundida também em Myanmar e na Indonésia, enquanto entrevistando marítimos e sindicalistas eu soube que existem casos de blacklisting também entre marítimos turcos, ucranianos, romenos, búlgaros e georgianos. No caso das listas negras, deveriam-se contar não somente os blacklisted (os cadastrados nas listas negras), mas todos aqueles sobre os quais o conhecimento da possibilidade de ser inserido em listas negras e seu efeito devastador nas vidas dos marítimos punidos e de suas famílias, especialmente em contextos de alto desemprego e em presença de dívidas a saldar, tem o efeito dissuasor de aceitar condições de trabalho de outra forma inaceitáveis.

Para todos os anos pelos quais está disponível a estimativa IER-BIMCO/ ISF sobre a disponibilidade mundial de força de trabalho marítima (2000,2005, 2010, 2015), o conjunto dos trabalhadores marítimos, que pertencem a nacionalidades para as quais as práticas dos adiantamentos e descontos (privadas e/ ou institucionais) e sobretudo do blacklisting (privado e/ou institucional) são espalhadas, nunca foi inferior a 18,2\% (em 2005), com o pico - sempre mínimo - de $38,2 \%$ em 2015 , sobre o total da força de trabalho marítima disponivel em escala mundial.

29 ILO, 2001, pp. 9-10. 
Existindo uma óbvia relação entre trabalho forçado e negação do direito à greve e à organização independente por parte dos trabalhadores, se incluimos o número trabalhadores marítimos, que trabalham sob sistemas jurídicos e políticos que reprimem ou poem sérios ou sérissimos entraves à possibilidade de organização autônoma dos trabalhadores marítimos e à sua possibilidade de contratar coletivamente ou de exercer o direito de greve, a percentual deles (calculada por defeito) sobre a força de trabalho marítima mundial em 2000, 2005, 2010, 2015, nunca desce abaixo de 31,0\% (2005), alcançando o pico - sempre mínimo - de 46,4\% em 2015.

\section{CONCLUSÕES}

Esta resenha das formas de trabalho forçado no setor marítimo e das relativas estimativas não é exaustiva; por falta de espaço, aqui apenas menciono os ulteriorers casos e formas: o abandono dos marítimos como forma de trabalho forçado; as violências psicológicas e físicas - que às vezes levam até ao assassinato - por razões disciplinares ou discriminatórias; o trabalho imposto à eventuais clandestinos encontrados a bordo, a discriminação sobre base nacional no acesso no setor ou em alguns segmentos dele; as práticas da atribuição de tarefas mais pesadas e menos remunerativas a bordo, como forma de punição ${ }^{30}$.

No caso das estimativas apresentadas neste artigo, elas se referem a diferentes dipositivos que produzem trabalho forçado e que muitas vezes se sobrepõem, particularmente para algumas nacionalidades de marítimos. No entanto, o resultado final é que não menos de um terceiro da força de trabalho marítima mundial é embridada nestes dispositivos no período entre 2000 e 2015.

A prolongada desanteção sobre o trabalho forçado no mar ou o fato de considerar como óbvias as formas de coerção no setor marítimo, exigiria de ser investigada. Entre outras razõs, penso que o reconhecimento do trabalho forçado no mar é complicado pelo fato de que muitas vezes o trabalho forçado é pensado como uma condição de servidão em ausência de compensação monetária e como condição continua ao longo do tempo. Em vez disso, como nós vimos, o trabalho forçado se enxerta sobre o trabalho assalariado e se reproduz normalmente em virtude da existência do código salárial. Além disso, a condição de trabalho mais abertamente forçado manifesta-se intermitentemente na vida do trabalhador, às vezes durante o mesmo dia de trabalho, como é o caso das horas trabalhadas por causa dos novos procedimentos de segurança, ou apenas em alguns lugares e dias, como no caso do confinamento no navio em alguns

30 A incidência percentual de algumas dessas formas de trabalho forçado é muito baixa: por exemplo, os abandonados representam, ao minímo, entre 0,05 e $0,2 \%$ sobre a força de trabalho marítima global disponível, dependendo do ano tomado como referência, mas esses casos extremos de degradação do trabalho ainda aparecem superiores as estimativas elaboradas por OIT sobre trabalho forçado em geral a terra. 
portos internacionais, ou apenas a bordo de alguns navios; da mesma forma delimitado é o tempo gasto trabalhando para descontar adiantamentos sobre salário exigidos pelos Estados ou por agências privadas.

Algumas questões problemáticas emergem da comparação dos resultados da análise do trabalho forçado no mar com as estimativas do trabalho forçado em terra elaboradas pela OIT. Um primeiro nó problemático está relacionado com a discrepância entre número e percentagem mínimas de trabalho forçado no mar e número e percentagem mínimas de trabalho forçado a terra. Não é que o trabalho forçado seja realmente tão mais relevante no mar do que a terra: o problema é que as estimativas minímas e conservadoras da OIT minimizam sua relevância tanto no mar quanto a terra.

Tenho observado acima que enquanto o CEACR da OIT detecta e denuncia normas que constituem dispositivos legais de trabalho forçado no setor marítimo, os relatórios da OIT não dedicam nem uma linha ao problema. Tal consideração pode ser estendida também para o trabalho em terra firme, desde que a partir de uma primeria resenha dos relatórios do CEACR é evidente uma grande discrepância entre o número de trabalhadores normados por sistemas jurídicos que preveem e promovem o trabalho forçado e as estimativas do número de trabalhadores forçados apresentadas nos relatórios da OIT a este respeito no século XXI.

Se tomarmos como referência somente o número dos empregados na indústria dos Estados denunciados pelo CEACR entre 2014 e 2016, por manter por sistemas jurídicos que preveem e promovem o trabalho forçado na indústria, uma percentagem não inferior a $10 \%$ (correpondendo aproximadamente a 80 milhões de trabalhadores) dos empregados totais no mundo na indústria deveria ser contada na estimativa miníma do trabalho forçado em escala internacional, ou seja, apenas este número e esta percentagem são mais de três vezes maiores do que a estimativa conservadora do total dos trabalhadores forçados no mundo, publicada no relatório da OIT de 2017.

É preciso também considerar que no setor marítimo os Estados são diretamente responsáveis ou co-responsáveis para a produção e reprodução de trabalho forçado em $98 \%$ dos casos ${ }^{31}$, enquanto à iniciativa privada é recon-

31 Desde mais de meio século, é recorrente a denúncia das bandeiras de conveniência e das condições de abuso dos marítimos, que são sinalizadas como mais frequentes nos navios registrados sob elas. A tal respeito, deve, no entanto, ser dito que não necessariamente os navios arvorando bandeiras de conveniência registram condições a bordo piores daquelas dos navios que arvoram bandeiras nacionais, nem que os Estados que oferecem bandeiras de conveniência assinaram menos convenções internacionais daquelas assinadas pelas grandes potências marítima estabilizadas.

Na verdade, os principais agentes do trabalho forçado marítimo não são os pequenos Estados paracoloniais apêndices de Estados ex-metropolitanos, nem Estados na beira da falência, como Libéria ou Camboja, os quais oferecem suas bandeiras para reabastecer escassas finanças - os principais agentes do trabalho forçado marítimo são os Estados históricos ou recentes for- 
duzivel uma percentagem não inferior a 10\% dos casos analisados nos vários anos, sempre para a questão da sobreposição dos dispositivos de coerção. Por outro lado, de acordo com a OIT, a responsabilidade dos Estados é muito mais limitada: 20\% dos casos em 2005, $10 \%$ em 2012, 16,5\% em 2017. Novamente, como tentei demonstrar em outra ocasião (Zanin, 2017), estamos em presença de um pesado subdimensionamento do problema.

As razões destas minimizações podem ser várias. Uma primeira razão é que os especialistas da OIT consideram apenas os trabalhadores diretamente punidos (para usar um exemplo do mundo marítimo, é como levar em conta apenas os marítimos cadastrados nas listas negras) e não elaboram estimativas minímas sobre o potencial número de ameaçados pela punição: esta escolha metodológica não implica apenas uma interpretação restritiva das convenções da OIT sobre trabalho forçado, mas sua negação de fato, desde que um elemento fundamental da definição de trabalho forçado é a "ameaça de uma pena" e não a execução da pena em cada caso singular. Uma segunda razão deve ser rastreada em um minimalismo dos direitos humanos centrado apenas em alguns casos de extrema degradação, e de uma forma significativamente maioritária das vezes em aqueles atribuíveis a atores individuais ou privados, isso talvez porque os especialistas da OIT confiem na aliança dos Estados no contraste a esses casos e temem comprometer a possível colaboração dos Estados para este fim, denunciando as responsabilidades destes.

Além das ideologias e do oportunismo político, deve ser dito que os casos mais degradantes e violentos de trabalho forçado não só podem permanecer endêmicos, mas até aumentar se a atenção e a ação não é redirecionada, reforçada e organizada não tanto para a possível colaboração dos aparelhos de Estado, mas em direção ao que poderíamos chamar de universo médio do trabalho forçado e daquele de qualquer maneira dependente; os próprios trabalhadores, de fato, se postos em condições para poder exercer uma própria autonomia de iniciativa sindical e política independente, sempre têm se expressado como os atores mais importantes para a emancipação do trabalho escravo e forçado, normalmente chocando-se com os aparelho de Estado.

\section{REFERÊNCIAS}

AMANTE, Margtas, Industrial Democracy in the Rough Seas: The Case of Philippine Seafarers, $1^{\circ}$ ed., Cardiff, SIRC, 2003.

BELSER, Patrick - COCK, Michä̈lle De - MEHRAN, Farhad, ILO Minimum Estimate of Forced Labour in the World, $1^{\circ}$ ed., Geneva, International Labour Organization, 2005.

necedores de massas conspícuas de trabalho marítimo, como as Filipinas ou a China, ou os Estados que impõem nos portos regras lesivas dos direitos humanos e contrárias as convenções internacionais sobre o trabalho marítimo, como os EUA. 
BIMCO/ISF, Manpower Update. The worldwide demand for and supply of seafarers. Main report, $1^{\circ}$ ed., Warwick, University of Warwick - Institute for employment research (IER), 2005.

BIMCO/ISF, Manpower Update. The worldwide demand for and supply of seafarers. Main report, $1^{\circ}$ ed., Warwick, University of Warwick - Institute for employment research (IER), 2010.

BIMCO/ISF, Manpower Update. The worldwide demand for and supply of seafarers. Main report, $1^{\circ}$ ed., Warwick, University of Warwick - Institute for employment research (IER), 2015.

ICFTU (International Confederation of Free Trade Unions), Annual Survey of Trade Union Rights Violations (2006), 2007. Disponível em: https://www.tssa. org.uk/download.cfm?docid=63FBD89E. Acesso em: 02/08/2018.

ILO (International Labour Organization), Report of the Committee of Experts on the Application of Conventions and Recommendations (General annual Reports and observations concerning particular countries), Geneva, ILO, 19322017.

ILO, Stopping forced labour. International Labour Conference $\left(89^{\text {th }}\right.$ session2001), $1^{\circ}$ ed., Geneva, ILO, 2001.

ILO (International Labour Organization - Sub-group of the High-Level Tripartite Working Group on Maritime Labour Standards), An Analysis of the Essential Aspects of Decent Work in the Maritime Context, $1^{\circ}$ ed., Geneva, ILO, 2002.

ILO (International Labour Office), Le coût de la coercition. Rapport du Directeur Général, Conférence International du Travail, 98 session, 2009, Geneva, Bureau International du Travail, 2009. Disponível em: www.ilo.org/ declaration. Acesso em: 23/09/2018.

ILO - Walk Free Foundation - IOM (International Organization for Migration), Global estimates of modern slavery: forced labour and forced marriage, $1^{\circ}$ ed., Geneva, ILO, 2017.

ITF (International Transport-workers Federation), Access denied. Implementing the ISPS Code, $1^{\circ}$ ed., London, ITF Publications, 2007.

LANE, Tony - OBANDO-ROJAS, Bernardo - WU, Bin - TASIRAN, Ali, Crewing the International Merchant Fleet, $1^{\circ}$ ed., Redhill, Lloyd's Register - Fairplay Ldt, 2002.

MONDAINI, Gennaro - CABRINI, Angiolo, L'evoluzione del lavoro nelle colonie e la Società delle Nazioni, 1ºd., Padova, CEDAM, 1931.

US DEPARTMENT OF TRANSPORTATION-Maritime Administration, Foreign-Flag Crewing Practices. A Review of Crewing Practices in US Foreign Ocean Cargo Shipping, $1^{\circ}$ ed., Washington (DC), US Department of Transportation-Maritime Administration, 2003. 
WU, Bin (2008), Vulnerability of Chinese contract workers abroad: A case of the working conditions and wages of Chinese seafarers, Nottingham, China Policy Institute - University of Nottingham, discussion paper n. 32, 2008. Disponível em: http://www.nottingham.ac.uk/cpi/publications/discussionpapers. Acesso em: 01/06/2018.

ZANIN, Valter, I forzati del mare. Lavoro marittimo nazionale, internazionale, multinazionale. Problemi metodologici e linee di ricerca, $1^{\circ}$ ed., Roma, Carocci, 2007.

ZANIN, Valter, Trabalho não livre, forçado, escravo: problemas definitórios e metodológicos para o estudo diacrônico-comparativo do fenômeno, In: REZENDE FIGUEIRA, Ricardo - ANTUNES PRADO, Adonia - GALVÃO, Edna Maria (orgs.), Trabalho escravo contemporâneo: estudos sobre ações a atores, $1^{\circ}$ ed., Rio de Janeiro, Mauad Editora Ltda., pp. 309-324, 2017. 
